\title{
rommhalina
}

(8)

\section{El mar en la Eneida}
Autor(es):
Alvar Ezquerra, Antonio
Publicado por: Imprensa da Universidade de Coimbra
URL persistente:
URI:http://hdl.handle.net/10316.2/45102
DOI:
DOI:https://doi.org/10.14195/978-989-26-1568-4_7

Accessed : $\quad$ 26-Apr-2023 15:58:09

A navegação consulta e descarregamento dos títulos inseridos nas Bibliotecas Digitais UC Digitalis, UC Pombalina e UC Impactum, pressupõem a aceitação plena e sem reservas dos Termos e Condições de Uso destas Bibliotecas Digitais, disponíveis em https://digitalis.uc.pt/pt-pt/termos.

Conforme exposto nos referidos Termos e Condições de Uso, o descarregamento de títulos de acesso restrito requer uma licença válida de autorização devendo o utilizador aceder ao(s) documento(s) a partir de um endereço de IP da instituição detentora da supramencionada licença.

Ao utilizador é apenas permitido o descarregamento para uso pessoal, pelo que o emprego do(s) título(s) descarregado(s) para outro fim, designadamente comercial, carece de autorização do respetivo autor ou editor da obra.

Na medida em que todas as obras da UC Digitalis se encontram protegidas pelo Código do Direito de Autor e Direitos Conexos e demais legislação aplicável, toda a cópia, parcial ou total, deste documento, nos casos em que é legalmente admitida, deverá conter ou fazer-se acompanhar por este aviso.

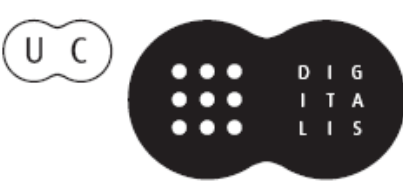




\section{O melhor é a água}

\section{Da antiguidade clássica aos}

nossos dias

José Luís Brandão \& Paula Barata Dias (coords.) 


\title{
El Mar en la ENeIDA
}

\section{(The Sea in the Aeneid)}

\author{
Antonio Alvar Ezquerra (antonio.alvar@uah.es) \\ Universidad de Alcalá \\ orcid.org/0000-0001-7654-0204
}

\begin{abstract}
Resumen - Virgilio lleva su reflexión sobre el mar mucho más lejos que sus predecesores y construye un universo literario y léxico en torno a él de sorprendente creatividad y duraderos resultados. La riqueza expresiva que muestra Virgilio deriva de las necesidades exigidas por su relato que se ambienta de manera muy considerable en el medio marino. Las prolijas écphrasis de tempestades, recorridos y paisajes marítimos, concursos y batallas navales, etc. le obligaron a resolver incontables problemas. Sin duda, el mar puso a prueba la capacidad creativa de Virgilio y él, con su poesía, contribuyó a transformar ese medio hostil en un espacio dominado y en un camino de civilización.
\end{abstract}

Palabras clave - Virgilio, Eneida, mare, aequor, altum, pontus.

Aвstract - Virgil takes his reflection on the sea much further than his predecessors and builds a literary and a lexical universe around him with surprising creativity and lasting results. The expressive richness that Virgil demonstrates derives from the needs demanded by his story, which is predominantly set in the marine environment. The prolific écphrasis of storms, routes and maritime landscapes, competitions and naval battles, etc forced him to solve countless problems. Undoubtedly, the sea puts to the test Virgil's creative capacity, and the poet contributed to the transformation of this hostile environment into a dominated space and a path of civilization with his lyrics.

Keywords - Virgil, Aeneid, mare, aequor, altum, pontus.

1. Cualquier lector de la Eneida sabe bien que en ella el mar desempeña una función narrativa muy importante, al menos en los primeros libros, los que tratan del periplo de los troyanos desde Ilion hasta las costas de Italia; y cualquier estudiante de latín que se haya enfrentado al texto de Virgilio sabe también que, para designar al mar y para referirse a todos los matices que pueden afectar a ese medio, el poeta de Mantua utiliza un número sorprendente de sinónimos y cuasi sinónimos -usados con suma precisión ${ }^{1}$, , que llegan a desesperar al aprendiz de traductor. Todo ello es verdad pero también lo es que, a través del estudio detallado de esas funciones narratológicas y del léxico y la fraseología empleados, es posible penetrar de manera más profunda en el arte creativo del poeta latino para desvelar cómo contribuye él a crear una lengua poética en latín al más alto

\footnotetext{
${ }^{1}$ Hasta el punto de que hay quienes creen que debió de contar con expertos marinos que le asesorasen, tal vez incluso el mismísimo Agripa (cf. Aen. 8.682); vide Peaks 1922: 201-209; Manfredi 1982: 3-18. La obra clásica sobre el asunto es, sin duda, la de De Saint-Denis 1935; también puede consultarse con provecho García Rodríguez 1994: 99-106.
} 
al tiempo que muestra a cualquier otro creador seguros senderos para lograr lo mismo en su lengua respectiva.

2. El mar es, en efecto, el escenario en el que se desarrolla la acción de buena parte de los primeros libros de la Eneida ${ }^{2}$. De hecho, superado el preámbulo de todo el poema épico en el libro I, la acción se inicia con la tempestad que la diosa Juno desata para impedir que Eneas y los suyos alcancen las costas de Italia desde su escala siciliana (50-156). Con justas razones, la potente descripción de esa tempestad ha sido estudiada en numerosas ocasiones y ha sido comparada con la descripción de otras tempestades literarias, de las que es modelo obligado3. Y no sería osado decir que la tempestad virgiliana alcanza un vigor tal que el mar ya no parece tan solo el escenario de la acción sino más bien el protagonista de la misma, hasta tal punto cobra vida y actúa sobre los mortales que han de padecerla. El resultado es que la flota dardania, tras grave quebranto y la pérdida de alguna de sus naves, llega dividida en dos grupos a las costas de Ấfrica, justo en la posición geográfica contraria a la prevista antes de iniciar la navegación desde Sicilia (157- 222).

El relato de la caída de Troya en el libro II no parece el lugar más propicio para la intervención del mar como escenario y, sin embargo, buena parte de la acción descrita se desarrolla en las playas de Troya (12-231) y del mar llegan las dos desgracias que destruirán la ciudad, primero las sierpes que devoran a Laocoonte y a sus hijos (199-231), luego los aqueos con sus naves (250-257).

El libro III es, de nuevo, un libro en el que el mar es el escenario constante de la narración, pues en él, como es bien sabido, se describe la larga navegación que los enéadas debieron afrontar desde su salida de Troya hasta la llegada, náufragos y abatidos, a Cartago donde el héroe cuenta a la reina Dido y a requerimiento de ella precisamente esas peripecias. La descripción conlleva referencias a un número significativo de enclaves del Mediterráneo, pues desde la partida en la Tróade se harán escalas en la cercana costa de Tracia (1-18), en la isla de Delos (69-120), en las Cícladas (121-127), en Creta (128-208), en las Estrófadas (209-269), en varias islas del Adriático y en Accio (270-288), en el Epiro, donde Héleno profetiza los caminos que han de seguir y las peripecias que han de sufrir (289-505) y, tras recorrer las costas del sur de Italia (506-553), en diversos lugares de Sicilia, en el último de los cuales, en Drépano, muere Anquises (554718). En esta ocasión, el mar se limita a la condición de marco narrativo y su

le asesorasen, tal vez incluso el mismísimo Agripa (cf. Aen. 8.682); vide Peaks 1922: 201-209; Manfredi 1982: 3-18. La obra clásica sobre el asunto es, sin duda, la de De Saint-Denis 1935; también puede consultarse con provecho García Rodríguez 1994: 99-106.

${ }^{2}$ Vide ahora Sullivan 1962: 302-309.

${ }^{3}$ Vide por ejemplo, Rodríguez-Pantoja Márquez 1985: 207-246; Cristóbal 1988: 125-148 y 2011: 21-41. También Gossage 1963: 131-136. 
protagonismo se debe tan solo al hecho de la larga duración del viaje.

En el libro IV el mar es solo el destino inmediato de los enéadas que se apresuran a escapar de Cartago (287-295, 393-431, 553-588), cumpliendo mandatos divinos -resumidos en la tajante orden de Júpiter (v. 237: Nauiget!) que ha de transmitir Mercurio a Eneas- bajo la desesperada mirada de Dido, pero debe notarse también el magnífico vuelo de Mercurio sobre el mar en su descenso desde el Olimpo a Cartago (238-258).

En el libro V se narran el regreso a las costas de Sicilia -forzado por una nueva tormenta de menor entidad, sin embargo, que la narrada en el libro I (1-34) - y, sobre todo, los famosos juegos fúnebres en honor de Anquises, al cumplirse un año de su muerte en ese mismo lugar. En el contexto de esos juegos fúnebres, la primera de cuyas pruebas es una regata (151-243), el mar cobra nueva importancia como escenario obligado de la acción deportiva. E1 libro concluye con el incendio de parte de las naves por las matronas troyanas, fatigadas por tanto tiempo de navegación y huida y deseosas ya de afincarse en algún lugar, con la fundación de la ciudad de Egesta donde quedan parte de los expedicionarios (604- 761) y con la partida de los restantes camino del destino final, las costas de Italia (762-834). Por fin, en este segundo intento por alcanzar el Lacio, los troyanos sufren la pérdida del piloto Palinuro, abatido por un golpe de mar en la tranquilidad de la noche (835-871).

Una vez alcanzadas las costas de Italia en el libro VI se diría que el mar pierde su importancia como escenario narrativo pero lo cierto es que no es exactamente así. Virgilio recurre a diversas estrategias que impiden olvidar la condición "marina" de la Eneida. La llegada a Cumas (1-8) y la visita a la sibila se aúnan con el episodio de la muerte de Miseno, sorprendido por las olas mientras tocaba la trompa en una roca (156-182), o con la narración ya en las bocas de los Infiernos, de Palinuro de su propio final tras caerse al agua (337-383). Del mismo modo, la descripción de la travesía de la laguna Estigia en la barca de Caronte (384416) se hace mediante el mismo léxico utilizado en anteriores travesías marinas. De modo que casi la mitad de este libro también está dominado por escenas relacionadas con el mar, la navegación y sus peligros.

Siguiendo las indicaciones dadas por Anquises, Eneas, al salir de los Infiernos, continúa en el libro VII su periplo, costeando Italia hasta llegar a la desembocadura del Tíber (1-36). Ahora sí, llegados al destino fijado por los hados, se diría que el mar ha de desaparecer de la narración, pero aún Juno divisa desde el promontorio del Paquino en Sicilia la escuadra troyana a punto de llegar a su destino y decide hacer un nuevo esfuerzo por impedírselo en tierra, si antes no ha podido lograrlo en el mar (286-322). Así, hasta bien entrado este libro no se urden los preparativos de las guerras en suelo itálico cuyo desarrollo será el motivo del resto del poema.

Con todo, a poco de iniciarse el libro VIII, Eneas es movido por un nuevo 
sueño (26-65) y navega otra vez, ahora el río Tíber, en busca de Palanteo, el reino de Evandro (66-101). La escasa acción de este libro se desarrolla, pues, tierra adentro pero, con todo, Virgilio dedica no menos de cuarenta versos a la descripción de una batalla naval, jla batalla de Accio!, grabada en el escudo que la diosa Venus regala a su hijo (671-713). Y mientras Eneas busca alianzas junto a Evandro, Turno ataca, ya en el libro IX, las posiciones troyanas situadas en la playa, de modo semejante a como se ubicaban los aqueos cuando sitiaban la ciudad de Troya (25-76). Y para salvar la escuadra se precisa la ayuda divina de Cibeles, pues de su monte Ida se talaron los árboles con que se fabricaron las naves, de modo que se transforman milagrosamente en ninfas que escapan raudas al mar y se libran del fuego destructor (77-122). Y, de nuevo, en el libro $\mathrm{X}$ se recupera durante una buena porción del mismo el escenario marino de la acción, mientras se describe el regreso de Eneas al campamento troyano (118-307), en cuyo transcurso se encuentra con sus viejas naves convertidas en raudas ninfas marinas (215-259) o en la escena en que Juno se ve obligada a retirar a su protegido Turno de la lucha para evitarle una muerte segura a manos de Eneas; la indeseada huida del rútulo se logra mediante una onírica estratagema que lo lleva, persiguiendo al vano fantasma del héroe troyano, a un navío y de ahí a altamar, para concluir su fuga en la ciudad rútula de Dauno, su padre (606-688).

Y, ahora sí, concluyen las escenas marinas de la Eneida, pues los dos últimos libros de desarrollan íntegramente en tierra firme.

3. A tenor de lo expuesto, se puede concluir que Virgilio se sirve de dos recursos para hacer presente el mar a lo largo de casi todo su relato: en primer lugar, se sirve del mar para construir con él grandes escenas a las que sirve de escenario, si bien en alguna ocasión el mar cobra un protagonismo propio de los seres animados. Tales escenas pueden ser, por ejemplo, la descripción de una tormenta (1. I), el relato de una singladura (1. III), la evocación de la agitada violencia marina en el estrecho de Sicilia (1. III), la retransmisión de una competición naval (1. V), la visión panorámica de la inmensa llanura del mar desde las alturas divinas (1. VII), la anticipación narrativa de una gran batalla en el mar a partir de su representación profética en el escudo del héroe (1. VIII) o el relato de la escapada misteriosa de Turno del campo de batalla mientras persigue un fantasma de Eneas (1. X). Otras veces, las escenas discurren en los espacios que median entre el mar y la tierra, es decir, en las playas, como cuando los troyanos visitan los reales aqueos recién abandonados, descubren el enigmático caballo, celebran sacrificios y asisten al terrible final de Laocoonte y sus hijos (1. II), o como cuando las troyanas, cansadas de navegar, incendian la flota (1. V), o como cuando muere Miseno arrebatado por una ola (1. VI), o como cuando las naves varadas se transforman por obra de Cibeles en ninfas para escapar del fuego 
rútulo huyendo al mar (1. IX). Podríamos recordar más episodios.

Pero también el mar forma parte del tejido microscópico del poema, pues hay referencias constantes a él y a su contexto, que sirven de soporte fugaz a recuerdos o evocaciones y a promesas, profecías y anticipaciones narrativas. Los ejemplos de estos procedimientos actualizadores del mar serían interminables.

4. Por si todo ello no bastara, Virgilio recurre a otro procedimiento poético para actualizar la presencia inagotable del mar en su poema: la comparación. A este respecto, conviene reparar en el sorprendente hecho de que apenas hay comparaciones de tema marino en los seis primeros libros ${ }^{4}$, aquellos que por la naturaleza de su argumento están más ambientados en escenarios marinos, y sin embargo las comparaciones de tema náutico son recurrentes en la segunda mitad del poema. No parece casual esa distribución; se diría que el poeta no desea sustraer al lector de la presencia del mar, ni aunque las acciones transcurran en tierra firme. Esas comparaciones se emplean en dos ocasiones en el 1. VII $\left(528-529^{5} ; 586-590^{6}\right)$, una en el 1 . VIII $\left(588-590^{7}\right)$, otra en el 1. IX $\left(710-715^{8}\right)$, tres en el 1. X $\left(357-359^{9} ; 693-696^{10} ; 763-765^{11}\right)$, una más en el 1. XI $\left(624-628^{12}\right)$

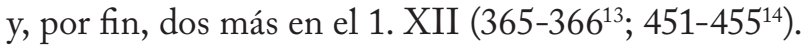

${ }^{4}$ Valga como excepción 5.594-595: delphinum similes qui per maria umida nando / Carpathium Libycumque secant.

${ }_{5}^{5}$ fuctus uti primo coepit cum albescere uento, / paulatim sese tollit mare et altius undas / erigit.

${ }^{6}$ ille uelut pelago rupes immota resistit, / ut pelagi rupes magno ueniente fragore / quae sese multis circum latrantibus undis / mole tenet; scopuli nequiquam et spumea circum / saxa fremunt laterique inlisa refunditur alga.

${ }^{7}$ qualis ubi Oceani perfusus Lucifer unda, / quem Venus ante alios astrorum diligit ignis...

${ }^{8}$ talis in Euboico Baiarum litore quondam / saxea pila cadit, magnis quam molibus ante / constructam ponto iaciunt, sic illa ruinam / prona trabit penitusque uadis inlisa recumbit; / miscent se maria et nigrae attolluntur harenae...

${ }^{9}$ magno discordes aethere uenti / proelia ceu tollunt animis et uiribus aequis; / non ipsi inter se, non nubila, non mare cedit; / anceps pugna diu, stant obnixa omnia contra...

${ }^{10}$ ille (uelut rupes uastum quae prodit in aequor, / obuia uentorum funis expostaque ponto, / uim cunctam atque minas perfert caelique marisque / ipsa immota manens)...

${ }^{117}$ quam magnus Orion, / cum pedes incedit medii per maxima Nerei / stagna uiam scindens, umero supereminet undas...

${ }^{12}$ qualis ubi alterno procurrens gurgite pontus / nunc ruit ad terram scopulosque superiacit unda / spumeus extremamque sinu perfundit harenam, / nunc rapidus retro atque sestu reuoluta resorbens I saxa fugit litusque uado labente relinquit.

${ }^{13}$ ac uelut Edoni Boreae cum spiritus alto / insonat / Aegaeo sequiturque ad litora fluctus...

${ }^{14}$ qualis ubi ad terras abrupto sidere nimbus / it mare per medium (miseris, heu, praescia longe / horrescunt corda agricolis: dabit ille ruinas / arboribus stragemque satis, ruet omnia late), / ante uolant sonitumque ferunt ad litora uenti. 
5. Mas, sin duda, lo que más ha llamado la atención de cuantos se han acercado al poema de Virgilio ha sido la variedad léxica con que el poeta designa al mar y la adjetivación que acompaña a esa variedad léxica ${ }^{15}$.

\subsection{Mare $^{16}$}

Naturalmente, el sustantivo común es el neutro mare, -is, que aparece en 59 ocasiones a lo largo del todo el poema, pero preferentemente en los libros de ambiente marinero: así, en el libro I se usa en 10 ocasiones, ninguna en el II, 8 en el III, ninguna en el IV, 14 en el V, 4 en el VI, 7 en el VII, 2 en el VIII, 4 en el IX, 8 el X, ninguna en el XI y 2 en el XII. De esas ocurrencias, son 44 en singular y 15 en plural; en 13 ocasiones se enfrenta a otros sustantivos como caelum y/o terra (cf., v. gr., 1. 58: ni faciat, maria ac terras caelumque profundum I quippe ferant rapidi secum uerrantque per auras; también 1.280, 598; 3.528; 5.9, $790,802 ; 7.301 ; 9.492 ; 10.57,162,695 ; 12.197)^{17}$; con frecuencia, como cabe esperar, va acompañado de algún adjetivo (omne, summum, ueliuolum, proruptum, placatum, medium, remensum, pronum, umidum, magnum, asperum, altum y altius, tumidum, inuium, inoffensum y en algunas ocasiones él es complemento de otro sustantivo, de un adjetivo sustantivado o de un adverbio (aequor, tantum, facies, domitor, numen, obice); por fin, en otras más está construido con el nombre propio de algún mar en concreto (v. gr. 5.52: Argolico mari). Además, es de notar que, cuando mare cumple función de sujeto o de objeto directo lo hace con verbos como ire, rubescere, tollere (sese), miscere (se), adlabere, cedere, en el primero de los casos, y como uerrere, despicere, tenere, fatigare, ueheri -1. 524: uecti omnia maria, en un uso a la griega-, dare, uoluere, ferire, petere, miscere, intrare, ferre, iurare -de nuevo en un uso a la griega-, mittere, exurere, sulcare, en el segundo. Por fin, en otras ocasiones el sustantivo reviste la forma de un dativo condicionado por el preverbio verbal, tal como ocurre en 1.84 (incubuere mari), o se construye con diversas preposiciones de acusativo como en 5.175, 808; 7.802 (in mare), en 3.695 (subter mare) o en 5.594, 628 (per mare).

Muchos de esos sustantivos, adjetivos o verbos resultan esperables (omne, summum, medium, magnum, tantum, altum, placatum, asperum, tumidum, inuium, domitor o numen -aplicado a Neptuno-, aequor, incluso facies, $y$, entre los verbos, despicere, intrare, sulcare...), otros parecen tautológicos (umidum), pero otros son, digámoslo así, pintorescos o sencillamente inesperados, por lo que están fuertemente cargados de fuerza connotativa, como ocurre con ueliuolum o como ocurre cuando mare aparece en función de sujeto o de objeto directo con los verbos

${ }^{15}$ Contamos con una reciente y completísima visión de conjunto sobre esta cuestión: Luque Moreno 2011. Vide también De Meo 1986:248-271.

${ }^{16}$ Vide Luque 2011: 29-79.

${ }^{17}$ Vide Castresana 1982: 245-258. 
rubescere, miscere, fatigare, iurare, exurere, etc.

Virgilio, a partir de usos -digámoslo así- normales, como altum mare (vide, v. gr., 7.200: qualia multa mari nautae patiuntur in alto; 10.197: ille / instat aquae saxumque undis immane minatur / arduus, et longa sulcat maria alta carina) o como aequor maris (3.495: nullum maris aequor arandum, donde el efecto expresivo se produce con la insólita juntura de arare con aequor maris, no del sustantivo aequor con maris), despliega otros mecanismos de designación extraordinariamente productivos y sobre los que, a su vez, desarrollará otros, explorando de ese modo las infinitas posibilidades del lenguaje y llevando la expresión poética a límites absolutamente insospechados. Así, en 7.528-530 (fluctus uti primo coepit cum albescere uento, / paulatim sese tollit mare et altius undas erigit, / inde imo consurgit ad aethera fundo), el adjetivo altum aparece en grado comparativo y ya no con el significado de 'profundo', como suele ocurrir, sino de 'alto', pues se refiere a la condición del mar encrespado por la tempestad.

\subsection{Altum/profundum ${ }^{18}$}

Tras el sustantivo mare y a partir de usos como los acabados de mostrar, Virgilio designa al mar tan solo con un adjetivo sustantivado, preferentemente altum, pero también en una ocasión profundum (12.263-264: petet tille fugam penitusque profundo / uela dabit). Altum aparece sustantivado en veinte ocasiones, quince de ellas en singular y cinco en plural, haciendo la salvedad de que, en 12.365-366, en el sintagma alto Aegaeo es difícil definir cuál de las dos palabras es el sustantivo y cuál el adjetivo. Así, resulta llamativo, por lo demás, el hecho de que ese adjetivo sustantivado puede complementarse, en ocasiones, o bien con otros adjetivos (además del ejemplo posible recién recordado, vid. 2.203: ecce autem gemini a Tenedo tranquilla per alta / (horresco referens) immensis orbibus angues / incumbunt pelago pariterque ad litora tendunt), o bien con complementos nominales (como es el caso de alta pelagi en 9.81: tempore quo primum Phrygia formabat in Ida / Aeneas classem et pelagi petere alta parabat, / ipsa deum fertur genetrix Berecyntia magnum / uocibus his adfata Iouem).

En estos casos, los verbos utilizados son esperables (iactare, uela dare, prospicere, ferre, ire, tenere, uocare, petere, etc.), como si se quisiera evitar al lector una doble pirueta estilística. Por fin, resulta significativo que la posición métrica preferida para altum (alto, alta) sea el pie final del hexámetro, pues ahí aparece nada menos que en dieciséis de las veinte ocurrencias.

Conviene advertir que Virgilio no siempre recurre al procedimiento de sustantivar un adjetivo con el fin de dar toda la variedad posible a su expresión; así, por ejemplo, otro adjetivo del mismo campo semántico que altum y profundum, como es el caso de imum, es utilizado en las tres ocasiones en que

${ }^{18}$ Vide Luque 2011: 280-292 y 300-312. 
aparece en contextos referidos al mar, en su condición adjetiva; así, en 3.421 con gurgite (atque imo barathri ter gurgite uastos / sorbet in abruptum fuctu), en 7.530 con fundo (inde imo consurgit ad aethera fundo) y en 9.119-120 con aequora (delphinumque modo demersis aequora rostris / ima petunt).

\subsection{Aequor / aequum ${ }^{19}$}

En llamativo contraste con la designación del mar apelando a su profundidad, Virgilio se refiere a él en nada menos que setenta y cuatro ocasiones con la palabra aequor ('la llanura'), subrayando su condición plana cuando se encuentra en calma, sin que el uso singular/plural se decante de manera clara por una $\mathrm{u}$ otra posibilidad pues se contabilizan treinta y cuatro ocurrencias en singular frente a cuarenta en plural.

En cuanto a usos sintagmáticos llamativos de este sustantivo, merece la pena notar su construcción como regente del sustantivo mare, según se lee en 2.780 (longa tibi exsilia et uastum maris aequor arandum) y en 3.495 (nullum maris aequor arandum), sintagma a partir del que fácilmente se desarrolla el empleo de aequor simplemente como sinónimo de mare. También, su aparición en próxima compañía de los sustantivos mare, fluctus, gurges $^{20} \mathrm{u}$ otros del mismo campo semántico para evitar la confusión que le podría producir al lector la metafórica polisemia de esta voz; ejemplos como 3.196-197 (continuo uenti uoluunt mare magnaque surgunt / aequora, dispersi iactamur gurgite uasto), 3.289290 (linquere tum portus iubeo et considere transtris; / certatim socii feriunt mare et aequora uerrunt), 3.662-665 (postquam altos tetigit fluctus et ad aequora uenit, / luminis effossi fluidum lauit inde cruorem / dentibus infrendens gemitu, graditurque per aequor / iam medium, necdum fluctus latera ardua tinxit) bastan y sobran, aunque podrían aducirse otros más (como 4.581-583, 5.140-143, 5.819-821 o 8.671-677).

Al igual que ocurre con el sustantivo mare, también aequor puede aparecer (si bien, esto solo ocurre en una ocasión) acompañando a un adjetivo procedente de un nombre propio (vide 1. 67: Tyrrhenum nauigat aequor).

Llama la atención el elevado número de verbos, de muy diferentes campos semánticos, a los que aequor sirve como sujeto o como objeto directo. Para la primera de las circunstancias, merece la pena señalarse el uso de aequor como sujeto de un verbo de acción como es ferre (5. 843: ferunt ipsa aequora classem); otros se indican más abajo. Para la segunda, cabe decir que algunos de los verbos resultan esperables, como es el caso de petere o prospicere; sin embargo, poseen gran carga estilística otros con los que la llanura del mar se trata como si fuera la de la tierra, como sucede con arare $(2.780,3.495)$, dehiscere (5.143), euertere

\footnotetext{
${ }^{19}$ Vide Luque 2011: 109-118.

${ }^{20}$ Para su uso como determinante de sal, Vide infra 4.13.
} 
(1.43), permetiri (3.157). Aún más pregnantes resultan las construcciones con placare (1.142), silere (1.164) y temperare (1.146) -que parecen tener sintagmas contrapuestos en los que aequor es sujeto del verbo quiescere (4.524, 7.7)-, con lustrare $(3.378,385)$ y uerrere $(3.290, \mathrm{~V} 778,8.674)$, con sternere (5.763; pues en 8.89 no se refiere a la llanura del mar) -cuyo opuesto sería la construcción aequora surgunt (8.197), con ciere (2.419), latere (4.582), premere (10.103), ruere (8.690), secare $(5.219,10.166)$, spumare (8.690) o temptare (2.176). Particularmente osadas parecen ya otras construcciones como las que se formulan con adlabi (10.269: donec uersas ad litora puppis / respiciunt totumque adlabi classibus aequor), o con misceri (4.411: totumque uideres / misceri ante oculos tantis clamoribus aequor), o con conscendere (1.381: bis denis Phrygium conscendi nauibus aequor), construcción muy llamativa en este caso, tratándose de una llanura, y de la que se diría que juega con la semántica de altum.

No faltan tampoco construcciones en las que aequor es objeto directo de verbos generalmente usados como intransitivos, tal como ocurre con certare (3.668: uertimus et proni certantibus aequora remis), o en las que se utiliza 'a la griega' como acusativo interno de verbos como nanigare -de la que parece una variante la construcción con currere (3.191: uela damus uastumque caua trabe currimus aequor; 5.235: di, quibus imperium est pelagi, quorum aequora curro)-, según ocurre precisamente en un pasaje (1.67) evocado poco más arriba. Ya Servio $(1.67,25)$ anota: NAVIGAT AEQVOR figura Graeca est; nos enim dicimus per aequor navigat. similiter etiam alio loco "terram, mare, sidera iuro", cum latinitas exigat, ut addatur praepositio per.

Nota aparte merece la variopinta adjetivación virgiliana a este sustantivo; algunos adjetivos son bien esperables como ocurre con inmensum, magnum, placidum, undosum o uastum; otros, como diuersum, hospitum, laeuum, saeuum o tutum, quizás no lo sean tanto; otros, tales como uentosum, conuulsum, reuolutum, summum (que parece contraponerse a altum o imum, de los que se dice luego), difícilmente podrían aplicarse a la llanura de tierra firme, y, aún menos, tumidum, cuyo uso en 1.142 (sic ait et, dicto citius, tumida aequora placat) o en 5.819-821 (caeruleo per summa leuis uolat aequora curru; / subsidunt undae tumidumque sub axe tonanti / sternitur aequor aquis, fugiunt uasto aethere nimbi) parece preparar al lector para denominaciones como aestus (vide 3.396-398: has autem terras Italique hanc litoris oram, / proxima quae nostri perfunditur aequoris aestu, / effuge; o bien, 8.674: aequora uerrebant caudis aestumque secabant); algunos más, de ninguna manera se podrían aplicar a las llanuras de tierra firme, como altum (6.5-7: At pius exsequiis Aeneas rite solutis, / aggere composito tumuli, postquam alta quierunt / aequora, tendit iter uelis portumque relinquit) o imum (9.119-120: delphinumque modo demersis aequora rostris /ima petunt). Pero quizás el adjetivo más llamativo de los que se aplican a aequor sea marmoreum, si bien es justo señalar que otros poetas antes de Virgilio ya lo utilizaron con ese mismo valor. Así, en 6.728-729 
se lee Inde hominum pecudumque genus uitaeque uolantum / et quae marmoreo fert monstra sub aequore pontus, con que se anticipa el muy osado lentus marmor, que se leerá poco después, en 7.28 (vide infra 4.15).

La ambigüedad calculada del poeta, por fin, llega a tal punto que en alguna ocasión es imposible decidir si aequor se refiere a una llanura terrestre o a la llanura de las aguas en calma; esa formidable ilusión semántica se logra en 8.9496, donde Eneas remonta el curso de un Tíber desbordado sobre la llanura del Lacio:

olli remigio noctemque diemque fatigant

et longos superant flexus, uariisque teguntur

arboribus, uiridisque secant placido aequore siluas.

En cuanto a las colocaciones métricas preferidas por Virgilio para las distintas formas de esta palabra, es preciso indicar que aequoris, aequore y aequora ocupan el quinto pie del hexámetro nada menos que en cuarenta y tres ocasiones, mientras que suministran tan solo en nueve el primer pie; notable resulta también que el nominativo/acusativo aequor se coloca en dieciséis ocasiones en el sexto pie.

Finalmente, conviene subrayar que también de aequor, y más concretamente del adjetivo aequus, $-a$, - um, ha extraído Virgilio un nuevo sustantivo, sinónimo de mare, insólito pero esperable de su fecundísimo arte creativo, a saber, aequum. Así en 9.67-68 se lee:

qua temptet ratione aditus, et quae uia clausos excutiat Teucros uallo atque effundat in aequum?

\subsection{Pontus ${ }^{21}$}

Otro sinónimo de mare, frecuentemente usado por Virgilio (concretamente, en veinticinco ocasiones) es el helenismo pontus, - $i$, cuya semántica incide en la condición del mar no como espacio de separación entre diversas tierras, sino

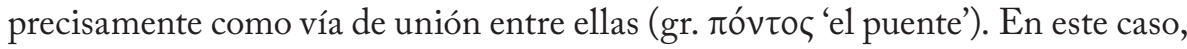
se utiliza tan solo en singular y proporciona en dieciocho ocasiones el sexto pie del hexámetro.

También pontus se construye con nombres de lugar, pero frente a mare y aequor que rigen a sendos adjetivos, en este caso la construcción se formula rigiendo a un nombre propio en genitivo (vid. 1.556: pontus Lybiae).

En cuanto a sus usos sintagmáticos, cabe decir que pontus se vincula a verbos similares a los ya vistos para aequor, creando por lo general junturas poco llamativas semánticamente (ponto, como dativo preverbial: dissicere, immergere,

${ }^{21}$ Vide Luque 2011: 235-241. 
incubare, opponere, submergere; o en construcción de ablativo absoluto: pererrare), que no siempre se corresponden con otras ya vistas en casos anteriores (pontus, como sujeto: apparere, claudere, ferire, ferre, habere, intremuere, misceri, premere, splendere, uenire; pontum, como objeto directo: legere, secare). Además, pontus, a diferencia de otros sinónimos, aparece escasamente adjetivado y, cuando lo está, los adjetivos que le acompañan no son tampoco demasiado significativos semánticamente (ingens, totus, uastus), salvo en algún caso como en 9.103, donde se construye con el adjetivo spumantem (mortalem eripiam formam magnique iubebo / aequoris esse deas, qualis Nereia Doto / et Galatea secant spumantem pectore pontum).

\subsection{Pelagus $^{22}$}

Un nuevo sinónimo de mare es pelagus (neutro del gr. $\pi \varepsilon ́ \lambda \alpha$ ○ৎ), donde a la semántica no matizada del sustantivo común se añade el sema de 'mar abierto', que se subraya en 5.212 con el adjetivo apertus (pelago decurrit aperto). Virgilio se sirve de este sustantivo nada menos que en cuarenta y tres ocasiones, casi siempre en los casos oblicuos del singular (pelagi/pelago; tan solo una vez en acusativo, vid. 5.8-11: Vt pelagus tenuere rates nec iam amplius ulla / occurrit tellus - maria undique et undique caelum-, olli caeruleus supra caput astitit imber / noctem hiememque ferens, et inhorruit unda tenebris) y, dada la estructura prosódica de la palabra (pělăgus), en interior de verso. A diferencia de otros sinónimos, nunca aparece acompañado de nombre propio (o adjetivo derivado) de lugar.

Pelagus complementa verbos de semántica esperable (adire, incumbere, uolare, errare, praeterlabare, prouehere, agere, tenuere, etc.) y suele aparecer escasamente adjetivado (remensum, apertum, serenum, languente); sin embargo, es frecuente su uso como complemento de sustantivos o adjetivos sustantivados (imperium, fragor, uolucris, gemitum, tempestatibus, undas, laborem, periclis, minas, erroribus, rupes, extrema, alta, deae, nymphae, recursus).

\subsection{Gurges $^{23}$}

Un nuevo sinónimo de gran carga semántica es gurges ('la garganta'), con que se subraya el carácter letífero del mar y sus remolinos. Virgilio se sirve de este sustantivo de manera no ocasional pues se registran en el poema hasta doce ocurrencias referidas al mar y otras referidas a las corrientes de diversos ríos (vide 6.296-298: Hinc uia Tartarei quae fert Acherontis ad undas. / turbidus bic caeno uastaque uoragine gurges / aestuat atque omnem Cocyto eructat harenam; 9.816-818: ille suo cum gurgite flauo / accepit uenientem ac mollibus extulit undis / et laetum sociis abluta caede remisit), además de otras no referidas a corrientes de agua

\footnotetext{
${ }^{22}$ Vide Luque 2011: 219-234.

${ }^{23}$ Vide Luque 2011: 461-464.
} 
(vide, v. gr., 7.703-705: nec quisquam aeratas acies examine tanto / misceri putet, aeriam sed gurgite ab alto / urgeri uolucrum raucarum ad litora nubem), siempre en singular, nunca acompañado de nombre propio de lugar ni de adjetivo derivado y normalmente proporcionando el quinto pie del hexámetro (once ocasiones). Los escasos adjetivos que acompañan a este nombre son estilísticamente poco relevantes (uastus, curuatus). Véanse, a modo de ejemplo, dos pasajes, 1.118-119:

Apparent rari nantes in gurgite uasto, arma uirum tabulaeque, et Troia gaza per undas.

Y 3.420-425, donde el sustantivo gurges es, además, complementado por el adjetivo imo y por el complemento del nombre barathri, insistiendo con fuerza en el terrible aspecto de Caribdis:
Dextrum Scylla latus, laeuum implacata Charybdis obsidet atque imo baratbri ter gurgite uastos sorbet in abruptum fluctus rursusque sub auras erigit alternos, et sidera uerberat unda. At Scyllam caecis cobibet spelunca latebris ora exsertantem et nauis in saxa trahentem.

\section{7. $U n d a^{24} /$ fuctus $^{25}$}

Dos sustantivos utilizados para designar comúnmente los efectos en la superficie de las aguas en movimiento (respectivamente 'la ola' y 'el oleaje'), son también utilizados por metonimia o sinécdoque con mucha frecuencia-mas no siempre- por Virgilio para referirse al mar. En efecto, en ocasiones unda y fuctus se refieren simplemente a olas y oleaje de ríos (por ejemplo, 1.100-101: ubi tot Simois correpta sub undis / scuta uirum galeasque et fortia corpora uoluit'; también 1.618; 3.302, 389; 9.817, etc.), lagos, estanques o fuentes (por ejemplo, 3.214215: nec saeuior ulla pestis et ira deum Stygiis sese extulit undis; 694-696: Alpheum fama est huc Elidis amnem / occultas egisse uias subter mare, qui nunc / ore, Arethusa, tuo Siculis confunditur undis; también 6.229, 295, 9.604, etc.), o incluso del mar, pero no necesariamente al mar en su conjunto. Sin embargo, hay casos en que cabría interpretar esos sustantivos como sinónimos de mar (1.65-66: namque tibi diuum pater atque hominum rex / et mulcere dedit fluctus et tollere uento; 103: fluctusque ad sidera tollit; 118-119: apparent rari nantes in gurgite uasto, / arma uirum tabulaeque et Troia gaza per undas; también 1.109, 127, 129, 147, etc.) y otros

${ }^{24}$ Vide Luque 2011: 89-105.

${ }^{25}$ Vide Dyson 1997: 449-457, donde se establecen paralelos expresivos con Lucrecio. Vide también Luque 2011:139-161. 
- generalmente en singular- en que, sin duda, se refieren de manera clara al mar (3.194-195: tum mibi caeruleus supra caput astitit imber / noctem biememque ferens, et inhorruit unda tenebris; 270: iam medio apparet fluctu nemorosa Zacynthos; 533: portus ab euroo fluctu curuatus in arcum; 554: tum procul e fluctu Trinacria cernitur Aetna; también 3.605, 662, etc.). La sinécdoque resulta particularmente intensa y atrevida en 7.228-230:

dilunio ex illo tot uasta per aequora uecti

dis sedem exiguam patriis litusque rogamus

innocuum et cunctis undamque auramque patentem.

$V n d a$ (no así fluctus) puede aparecer, como otros sinónimos de mare, también en asociación con adjetivos derivados de topónimos, como ocurre, por ejemplo, en 1.596 (Libycis ereptus ab undis), 3.384 (ante et Trinacria lentandus remus in unda), 5.789 (de nuevo Lybicis undis) o bien 11.405 (amnis et Hadriacas retro fugit Aufidus undas).

Además, es pertinente subrayar la adjetivación, sin duda sorprendente, de unda con spumosa y con spumea, tal como se lee respectivamente en 6.174 (inter saxa uirum spumosa immerserat unda) y en 10.212 (spumea semifero sub pectore murmurat unda). Nada extraño, pues, que en otros lugares se emplee el sustantivo spuma como sinónimo de mare (vide infra 4.12).

Por fin, merece la pena notar que, frente a la muy variable disposición de fluctus y sus respectivas formas casuales en el hexámetro, unda y sus variantes casuales suele aparecer conformando el sexto pie, pues de las setenta y nueve ocasiones en que se lee, se coloca en ese lugar nada menos que en sesenta.

\subsection{Vadum $^{26} /$ fretum $^{27}$}

Del mismo modo, Virgilio utiliza otros sustantivos para designar al mar, más allá de sus sentidos originales con que son utilizados en otras ocasiones. Así ocurre con uadum ('el paso', 'el mar poco profundo', 'los bajíos'), que en 5158 (et longa sulcant uada salsa carina) o en 7.197-198 (quae causa rates aut cuius egentis / litus ad Ausonium tot per uada caerula uexit?), acompañado de adjetivos adecuados (salsa, caerula), es otro sinónimo de mar; o que en 5.615-616 (heu tot uada fessis I et tantum superesse maris!) se opone precisamente a mare en una hendíadis más que probable.

Y también ocurre que uadum, en plural y en su acepción original de 'lugar por el que se puede caminar' y, de ahí, 'lugar de aguas poco profundas', es adjetivado en alguna ocasión por Virgilio con breuis, subrayando la condición muy escasa

\footnotetext{
${ }^{26}$ Vide Luque 2011: 359-372.

${ }^{27}$ Vide Luque 2011: 165-190.
} 
del nivel del agua; así, en 5.221-222 (breuibusque uadis frustraque uocantem/ auxilia); pues bien, a partir de esa construcción, se sirve de ese mismo adjetivo plural ya sustantivado en otros lugares, como por ejemplo en 1.110-111 (tris Eurus ab alto / in breuia et Syrtis urget) o 10.288-290 (multi seruare recursos / languentis pelagi et breuibus se credere saltu, / per remos alii). Sin duda, este uso tiene mucho que ver con el griego $\beta \rho \alpha \chi \varepsilon ́ \alpha$, según explica Servio (ad 1.111).

De manera paralela sucede con fretum ('el estrecho', metonímicamente, 'el mar entre tierras'; siempre en plural), que en lugares como 1.607 (in freta dum fluiii current), 3.127 (et crebris legimus freta concita terris), 5.141 (adductis spumant freta uersa lacertis) y como 5.627-628 (cum freta, cum terras omnis, tot inhospita saxa/sideraque emensae ferimur), 10.147 (media Aeneas freta nocte secabat) o 10.210 (bunc uehit immanis Triton et caerula concha / exterrens freta, en este caso otra vez acompañado del adjetivo caerula), es un nuevo sinónimo de mar.

\subsection{Aestus $^{28}$}

Quizás más sorprendente sea el uso metafórico por mare del sustantivo aestus, de semántica imprecisa pues designa tanto el movimiento de las llamas como el permanente movimiento de la superficie del mar, al igual que el brillo y el calor (real o aparente, pues en el caso del mar, su movimiento y la espuma consecuente se podrían asimilar al del agua en ebullición) de esos elementos. Por supuesto, no siempre aparece en la Eneida con este uso metafórico pues Virgilio lo emplea también con la acepción de 'calor intenso', propio de las llamas (véase, por ejemplo, 2.706, 759) o propio de la estación veraniega (véase, por ejemplo, 7.495), lo que le hace sinónimo de aestas, con quien está en relación etimológica, incluso en la acepción, nuevamente metafórica, de los tormentos del alma, como ocurre en 4.532, 564, 8.19 o 12.486, conformando en casi todos esos casos la cláusula fuctuat aestu (IV 564: concitat aestus).

Mas Virgilio extiende el campo semántico del sustantivo en expresiones como 1.106-107 (bi summo in fluctu pendent; his unda debiscens/terram inter fluctus aperit, furit aestus harenis) o como en 3.396-398 (has autem terras Italique hanc litoris oram, / proxima quae nostri perfunditur aequoris aestu, / effuge), donde aestus ('el mar en movimiento' - por efecto de la marea o del viento, no necesariamente perjudicial- e incluso 'embravecido') resulta ser la antítesis de aequor ('el mar en calma'). Otros ejemplos similares pueden leerse en 3.557 (exsultantque uada atque aestu miscentur harenae), 8.673-674 (et circum argento clari delphines in orbem / aequora uerrebant caudis aestumque secabant), 10.290-293 (speculatus litora Tarchon, / qua uada non sperat nec fracta remurmurat unda, / sed mare inoffensum crescenti adlabitur aestu, / aduertit subito proras sociosque precatur), 687 (labitur alta secans fuctuque aestuque secundo) o 11.627-628 (nunc rapidus retro atque aestu

${ }^{28}$ Vide Luque 2011: 123-137. 
reuoluta resorbens / saxa fugit litusque uado labente relinquit). La adjetivación con crescens y con secundus resulta esperable dentro de la acepción del movimiento de la superficie marina como consecuencia de la subida de la marea alta.

Quizás más llamativo sea el uso de aestus en un pasaje como 3.419 (uenit medio ui pontus et undis / Hesperium Siculo latus abscidit, aruaque et urbes / litore diductas angusto interluit aestu) con un adjetivo como angustus.

$\mathrm{Y}$ a partir de este sustantivo, Virgilio no tiene ningún problema en usar el verbo aestuo, con la acepción de 'moverse', 'agitarse', 'fluctuar', tal como ocurre en 6.296-297 (turbidus bic [Acheron] caeno uastaque uoragine gurges / aestuat atque omnem Cocyto eructat harenam).

\subsection{Stagnum ${ }^{29}$}

También dispone Virgilio de un sustantivo, stagnum, de nuevo metafórico, para referirse al mar, si bien no al mar 'estancado', en calma o apacible, sino, por el contrario, al mar agitado, de acuerdo con una extensión semántica ciertamente nada evidente y poco explicable. Así, en 1.124-127:

Interea, magno misceri murmure pontum emissamque hiemem sensit Neptunus, et imis stagna refusa uadis; graniter commotus, et alto prospiciens summa placidum caput extulit unda.

$\mathrm{O}$ en 10.764-765 (cum pedes incedit medii per maxima Nerei / stagna uiam scindens, umero supereminet undas).

En otros lugares, como 6.323 (Cocyti stagna alta uides Stygiamque paludem), sin embargo, la acepción de stagnum como 'estanque', 'charca', 'laguna' (en ese caso, 'profundo', frente a palus, que parece designar una 'laguna poco profunda') es indiscutible.

\subsection{Barathrum}

Aún más. Aunque el sustantivo barathrum designa 'el báratro', 'el infierno', 'lo que está debajo' (vide 8.245), Virgilio se permite usarlo en la acepción de 'la profundidad abisal del mar', subrayando el significado de gurges, en un lugar como 3.420-423 (vide supra 4.6).

\subsection{Spuma (salis) ${ }^{30} /$ mons (aquae)/tanta molis}

La prodigiosa capacidad creativa virgiliana recurre a otros muchos procedimientos para designar al mar, subrayando de paso alguna de sus características

\footnotetext{
${ }^{29}$ Vide Luque 2011: 249-255.

${ }^{30}$ Vide Luque 2011: 355-358.
} 
o circunstancias, elevando siempre el discurso poético hasta límites inimaginables. Es el caso del empleo de spuma, acompañado o no del determinante salis, como sinónimo de mar; así, en 1.35 (uela dabant laeti et spumas salis aere ruebant) o en 3.207-208 (haud mora, nautae / adnixi torquent spumas et caerula uerrunt; verso repetido en 4.583). Y, en relación con este sustantivo, no tiene nada de particular que Virgilio emplee los adjetivos spumosus, spumeus (vide supra 4.7) o spumans (2.209: fit sonitus spumante salo) para acompañar a sustantivos marinos, o el verbo spumare, como sinónimo de navigare, como ocurre, por ejemplo, en 10.208 (spumant uada marmore uerso). Sintagmas similares se logran también con mons más el determinante aquae, tal como ocurre en 1.105 (insequitur cumulo praeruptus aquae mons). $\mathrm{O}$, por fin, mediante la unión de un indefinido ponderativo con un sustantivo, como ocurre con el sintagma tanta molis, en plural, en 1.134 (et tantas audetis tollere moles?).

\subsection{Sal ${ }^{31} /$ salum $^{32}$}

Y, si el sustantivo sal puede determinar a sustantivos como spuma (en plural), con menos dificultad podrá hacerlo con otros, como campus $^{33}$ o aequor para designar al mar. Así, en 10.213-214 se lee:

Tot lecti proceres ter denis nauibus ibant subsidio Troiae et campos salis aere secabant.

$\mathrm{Y}$ en 3.384-386:

Ante et Trinacria lentandus remus in unda et salis Ausonii lustrandum nauibus aequor.

Ennio había ido incluso más lejos que Virgilio pues no tiene inconveniente en emplear el sustantivo sale (sic, nominativo) con el adjetivo caeruleum como sinónimo de mare en Ann. 14.385 (378 Skutsch: Caeruleum spumat sale conferta rate pulsum).

Por fin, Virgilio no tiene inconveniente en emplear el sustantivo neutro salum $^{34}$ (de hecho, ya lo empleó, aunque como masculino, Ennio en Hecuba 179 Jocelyn: undantem salum), como sinónimo de mar y, en concreto del mar agitado,

${ }^{31}$ Vide Luque 2011: 243-244.

${ }^{32}$ Vide Luque 2011: 245-247.

${ }^{33}$ Vide Luque 2011: 119-121. Sin embargo, el ejemplo por él aducido de campus en 5.127128 no debe entenderse como sinónimo de mare, pues se refiere a la superficie de la roca que se alza sobre la olas. Plauto, en Trin. 834, había empleado el sintagma caeruleos per campos, para referirse al mar.

${ }^{34}$ Vide Luque 2011: 245-247. 
si tiene que ver con el griego ó $\sigma \alpha \dot{\lambda} \lambda$ o५, o del mar como extensión de agua salada, si tiene que ver con sal, según ocurre en 1.534-538 (y en 2.209; vid. supra 4.12):
Hic cursus fuit, cum subito adsurgens fluctu nimbosus Orion in uada caeca tulit penitusque procacibus Austris perque undas superante salo perque inuia saxa dispulit; buc pauci uestris adnauimus oris.

\subsection{Aruum $^{35}$}

De la constante asimilación del mar con una inmensa llanura que se puede cortar (secare), hendir (dehiscere, infindere), barrer (uerrere), voltear (uoluere) o sencillamente arar (arare), se explican bien los usos metonímicos de aequor o de campus, ya señalados en 4.13, y también el de aruum, relacionado etimológicamente con arare, máxime si va acompañado de un adjetivo formado a partir del nombre propio Neptunus, como tantos otros con que se designan de manera precisa los diferentes mares (Aegaeus, Lybicus, etc.), según se dice, en esta ocasión para referirse al mar de manera muy genérica, en 8.695: arua noua Neptunia caede rubescunt.

\subsection{Marmor $^{36} /$ marmoreus}

No podía faltar en Virgilio una designación del mar muy llamativa y tal vez de raigambre homérica, a saber, la de marmor, empleada por el mantuano en 7.25-30:

Iamque rubescebat radiis mare et aethere ab alto Aurora in roseis fulgebat lutea bigis, cum uenti posuere omnisque repente resedit flatus et in lento luctantur marmore tonsae, atque hic Aeneas ingentem ex aequore lucum prospicit.

Y reiterada en otros versos de ese mismo libro, 7.718-719:

quam multi Libyco uoluuntur marmore fluctus, saeuus ubi Orion hibernis conditur undis

\footnotetext{
${ }^{35}$ Vide Luque 2011: 119-121.

${ }^{36}$ Vide Luque 2011: 201-204.
} 
Y aún otra vez en 10.208:

it grauis Aulestes centenaque arbore fluctum

uerberat adsurgens, spumant uada marmore uerso.

Esas designaciones tan osadas son posibles porque antes, en 6.728-729 (inde hominum pecudumque genus uitaeque uolantum / et quae marmoreo fert monstra sub aequore pontus), Virgilio ha utilizado el adjetivo marmoreum junto al sustantivo aequore, subrayando, sí, la suave textura y el brillante aspecto de la superficie del mar en calma o pero también quizás la blancura emanada de la espuma de las olas. Es cierto que ya Lucrecio se había servido de ese adjetivo para calificar al mar en 2.763-767 (y 775), e incluso se había servido de una comparación muy explícita para asemejar los oleajes llenos de espuma al mármol blanco:
perfacile extemplo rationem reddere possis,
cur ea quae nigro fuerint paulo ante colore,
marmoreo fieri possint candore repente,
ut mare, cum magni commorunt aequora venti,
vertitur in canos candenti marmore fluctus.

Y también Ennio, por su parte, ya anticipaba en Ann. 384 (Skutsch 377: uerrunt extemplo placidum mare: marmore flauo / caeruleum spumat mare conferta rate pulsum $)^{37}$ la comparación, siguiendo, sin duda, el modelo homérico de $\mathrm{Il}$.

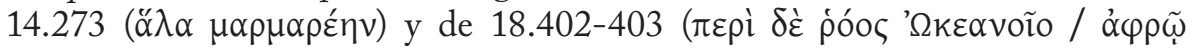

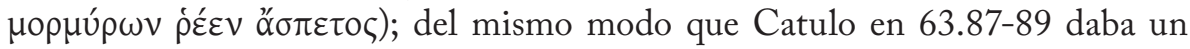
paso más en la conformación de la metáfora al decir: at ubi umida albicantis loca litoris adiit, / teneramque vidit Attin prope marmora pelagei, / facit impetum. Pero Virgilio la asienta de manera definitiva y segura, prescindiendo en 7.28 de los sustantivos explícitamente referidos al mar (mare caeruleum en Ennio, mare, aequora y canos fluctus en Lucrecio, pelagei en Catulo) ${ }^{38}$.

En cuanto a la adjetivación que acompaña al sustantivo, resulta de enorme osadía la utilización de lentus, con que, sin duda, se quiere subrayar la dificultad de mover con los remos las pesadas naves troyanas sobre un mar en calma absoluta o calma chicha (7.27-28), transfiriendo por enálaje a la superficie del mar la adjetivación que correspondería a las naves, así como la aplicación de un adjetivo derivado de un corónimo (7.718), como se hace en otras ocasiones con otras designaciones del mar, según ha quedado dicho. Por fin, si en 7.718 se

\footnotetext{
${ }^{37}$ Apud Gell. II 26, 21, 6 (Marshall).

${ }^{38}$ No así en 7.718 , donde aparece fluctus junto a marmore, ni en 10.208 , donde, tras el fluctum del v. 207, aparece uada junto a marmore. Tan solo de manera indirecta tonsae en 7.28 hace referencia al contexto marino.
} 
emplea el verbo uoluuntur con el sujeto fluctus, actuando marmore Lybico como un complemento circunstancial, resulta más fácil comprender en 10.208 el sintagma marmore uerso, no menos osado que los anteriores.

Por lo demás, Virgilio se ha podido dejar seducir por la indudable homonimia entre mare y marmor y por la comodidad que proporciona una palabra de estructura dactílica para conformar el quinto pie del hexámetro, posición en que aparece siempre este sustantivo (en ablativo, marmore).

\subsection{Caerul(e) um ${ }^{39}$}

Estos dos adjetivos de color - del color azul, concretamente- se suelen aplicar a todo lo que tenga que ver con el mar (también con el cielo) e incluso con ríos y otros medios acuáticos, sea de color azul o no; así, en 7.198 (uada caerula) o en 10.209-210 (caerula freta) y en donde ya el adjetivo no tiene por qué calificar el color de los sustantivos sino su condición marina. Virgilio, a partir de su frecuente uso, sustantiva también, como lo habían hecho otros poetas antes que él, el adjetivo caerulus (pero no el adjetivo caeruleus, sin duda por razones métricas pues varios casos presentarían tres breves seguidas) para designar específicamente al mar (no al cielo, por contra, como sí hacen otros poetas, como Ennio y Lucrecio), bajo la forma de nominativo/acusativo plural neutro, caerula, de nuevo muy apropiada por su estructura prosódica para suministrar el quinto pie del hexámetro, posición en que aparece las tres veces que Virgilio usa este sustantivo. Así, en 3.208 (repetido en IV 583) se lee adnixi torquent spumas et caerula uerrunt; y en 8.672, sed fluctu spumabant caerula cano.

\subsection{Oceanus ${ }^{40}$}

Por fin, Virgilio se sirve en varias ocasiones del nombre propio Oceanus (del griego ' $\Omega \kappa \varepsilon \alpha v o ́ \varsigma$ ) para referirse no a la divinidad, hijo primogénito de Urano y Gea, sino al mar y, probablemente, en su origen, al mar exterior que circunda el disco de la tierra, y, de manera muy particular, el Atlántico; de hecho, aunque resulte sorprendente, en la Eneida el sustantivo Oceanus solo se emplea en la acepción de mar, no como nombre de un dios, salvo en un caso ambiguo, 4.129 (repetido en 11.1: Oceanum interea surgens Aurora reliquit, donde, con todo, es más probable que se refiera al mar exterior en su zona occidental -el Atlántico-, pues no se conoce que Océano haya sido esposo o amante de la Aurora). Así, en 2.250 se lee:

${ }^{39}$ Vide Luque 2011: 317-321.

${ }^{40}$ Vide, ahora, los diferentes trabajos de Paulian sobre el Océano: 1975: 53-58; 1976: XII-XIV y, sobre todo, 1978: 23-29. También Knox 1989: 265. También, obviamente, Luque 2011: 209-217. 
nascetur pulchra Troianus origine Caesar, imperium Oceano, famam qui terminet astris, Iulius, a magno demissum nomen Iulo.

Y hay usos similares en 1.745-746 (quid tantum Oceano properent se tingere soles / hiberni), 2.250 (uertitur interea caelum et ruit Oceano nox), 4.480-481 (Oceani finem iuxta solemque cadentem / ultimus Aethiopum locus est), 7.225-226 (audiit et si quem tellus extrema refuso/summouet Oceano) o bien 8.588-589 (it medio chlamyde et pictis conspectus in armis, / qualis ubi Oceani perfusus Lucifer unda).

\section{Conclusión}

Virgilio lleva su reflexión sobre el mar mucho más lejos que sus predecesores ${ }^{41}$ y construye un universo literario y léxico en torno a él de sorprendente creatividad y duraderos resultados ${ }^{42}$. Apenas hay recurso encontrado por los que le precedieron para referirse al mar que no haya utilizado y llevado a sus últimas consecuencias el poeta de Mantua. Y, una vez que él marcó caminos seguros, facilitó la creatividad de los que le siguieron, de modo que, por si no bastaran los recursos por él empleados, otros, sobre todo poetas, ensancharon las posibilidades expresivas.

Naturalmente, la riqueza expresiva que muestra Virgilio deriva de las necesidades exigidas por su relato que, como decíamos, se ambienta de manera muy considerable en el medio marino. Las prolijas écphrasis de tempestades, recorridos y paisajes marítimos, concursos y batallas navales, etc. le obligaron a resolver incontables problemas. Bastaría con repasar el uso del léxico relacionado directamente con el mar, en pasajes muy conocidos, para cobrar cabal conciencia de su habilidad para solucionar lo que a otros antes de él y en cualquier lengua resultaría de muy difícil ejecución. Sirvan como ejemplos los lugares en que Virgilio describe diferentes tormentas marinas, como por ejemplo 1.81ss., 3.194ss. o 5.8ss., sobre los que han fijado en numerosas ocasiones su atención los estudiosos ${ }^{43}$; pero podrían aducirse otros no menos ilustrativos, como el pasaje 3.410-425, la descripción de la laguna Estigia y el Aqueronte en 6.295-371, la del escudo de Eneas en 8.671-713 o, en menor medida, la comparación incluida en 11.624-628.

Sin duda, el mar puso a prueba la capacidad creativa de Virgilio y Virgilio supo estar a la altura de ese inmenso reto. Él, con su poesía, contribuyó a transformar ese medio hostil a los romanos en un espacio dominado y en un camino de civilización.

\footnotetext{
${ }^{41}$ Vide Hodnett 1919: 67-82.

${ }^{42}$ Vide Zoicas 1991: 39-43.

${ }^{43}$ Además de los trabajos citados en n. 3, vide ahora Luque 2011: 467-482.
} 


\section{Bibliografia}

Cristóbal, V. (1988), "Tempestades épicas”, Cuadernos de investigación filológica 14: $125-148$.

Cristóval, V. (2011), "La tempestad como tópico literario", in Alvar Nuño (dir.), El viaje y sus riesgos. Los peligros de viajar en el mundo greco-romano. Madrid, 21-41.

De Meo, C. (1986 2a ed.) "La lingua del mare e della navigazione", in Lingue tecniche del latino. Bolonia, 248-271.

De Saint-Denis, E. (1935), Le rôle de la mer dans la poésie latine. París.

Dyson, J. T. (1997), "Fluctus irarum, fluctus curarum: Lucretian religio in the Aeneid”, AJPh 118: 449-457.

García Rodríguez, E. (1994), "El mar de Eneas y el mar de los descubridores", in Universidad Abierta (Los mares de griegos y romanos. Sexto coloquio de estudiantes de Filología Clásica, Valdepeñas 6-8 de julio de 1994), 12: 99-106.

Gossage, A. J. (1963), “Aeneas at sea”, Phoenix 17: 131-136.

Hodnett, M. P. (1919), “The sea in roman poetry”, Classical Journal 15: 67-82.

Knox, P. E. (1989), “Ruit oceano nox”, CQ 39: 265.

Luque Moreno, J. (2011), 'Mare Nostrum'. Reflexiones sobre el léxico latino del mar. Granada, EUG.

Manfredi, V. (1982), "Il consulente navale di Virgilio per l'Eneide", Aevum 56: 3-18.

Paulian, A. (1975), "Le thème littéraire de l'Océan”, Caesarodunum 10: 53-58.

Paulian, A. (1976), "L'Océan et les Romaines", Caesarodunum 11: XII-XIV.

Paulian, A. (1978), "Paysages océaniques dans la littérature latine”, Caesarodunum 13: 23-29.

Peaks, M. B. (1922), “Vergil's seamanship”, Classical Weekly 15: 201-209.

Rodríguez- Pantoja Márquez, M. (1985), “Una lectura de temas épicos latinos: la 'tempestad literaria' en Virgilio y Ovidio”, Revista de Filología (Univ. de La Laguna) 4: 207-246;

Sullivan, F. A. (1962), "Some Vergilian seascapes", CJ 57: 302-309.

Zoicas, L. (1991), “Poétique des éléments dans l'Énéide: II, L'eau”, StudClas 27: 39-43. 